\title{
Changes in Flight Period Predict Trends in Abundance of Massachusetts Butterflies
}

\author{
James Michielini ${ }^{1}$, Erik Dopman ${ }^{1}$, and Elizabeth Crone $^{1}$ \\ ${ }^{1}$ Tufts University
}

May 6, 2020

\begin{abstract}
Phenological shifts are well-documented in the ecological literature. However, their significance for changes in demography and abundance is less clear. We used 27 years of citizen science monitoring to quantify trends in phenology and relative abundance across 89 butterfly species. We calculated shifts in phenology using quantile regression and shifts in relative abundance using list length analysis and counts from club trips. Elongated activity periods within a year were the strongest predictor of increases in relative abundance. These changes may be driven in part by changes in voltinism, as this association was stronger in multivoltine species. Some species appear to be adding a late-season generation while other species appear to be adding a spring generation, revealing a possible shift from vagrant to resident. Our results emphasize the importance of evaluating phenological changes throughout species' activity periods and understanding the consequences for such climate-related changes on viability or population dynamics.
\end{abstract}

\section{Introduction}

Phenological shifts, changes the timing of species life history events, have become one of the best-documented signatures of anthropogenic climate change (Forrest \& Miller-Rushing, 2010; Parmesan \& Yohe, 2003). Many prominent studies of phenology have focused on the timing of reproduction, especially in plants (Parmesan \& Yohe, 2003). Some have documented shifts in seasonal migration (Møller et al., 2008). Others have documented changes in emergence from or entry into dormant life stages, including hibernation in vertebrate animals (Inouye, 2000), leaf-out periods for trees (Polgar \& Primack, 2011), and diapause in insects (Bale \& Howard, 2010). Although the majority of past studies have demonstrated advances in phenology associated with climate warming, there is considerable variation, with some species delaying phenology (Fric et al., 2020; Forister \& Shapiro, 2003; Roy \& Sparks, 2000).

Despite widespread documentation of changes in phenology, few empirical studies have tested whether phenological changes are associated with long-term trends in population size (Ramula et al., 2015). In terrestrial warming experiments, plants with earlier phenology in warmed plots tended to have higher biomass, growth, and/or reproduction, suggesting that phenological advances represent adaptive responses to environmental change (Cleland et al. 2012). Advanced phenology was also positively associated with long-term population trends of plants in Concord, Massachusetts (Willis et al. 2008) and may be beneficial for insect populations that can avoid competition for resources or feed on a wider range of vegetation (Rathcke \& Lacey, 1985). Nevertheless, changing phenology has also been shown to harm species, if changes lead to phenological mismatches with resources or interacting species (Both et al., 2006).

For insects, changes in phenology often arise through changes in the timing of entry into diapause, as well as timing of spring emergence (Bale et al., 2002). Many insect species exhibit geographically variable patterns of voltinism (number of broods within a year) based on location within their range. Under a warming climate, populations which were formerly thermally restricted in parts of their range may be capable of producing 
an additional generation within the extended growing season (Kozak et al., 2019; Grevstad \& Coop, 2015; Mitton \& Ferrenberg, 2012; Altermatt 2010; Tobin et al., 2008) which could be beneficial or detrimental for populations. Species that can successfully add a generation in the extended growing season may benefit from another bout of reproduction, leading to higher overall population growth rates (Kerr et al., 2020; Kerr et al., 2019), and the potential for more rapid evolutionary responses to climate change (Chevin et al., 2010). In spite of its potential benefits, an increase in voltinism can also be detrimental to insects. Mismatched phenological cues could cause a population to start an additional generation that fails to reach its diapausing life stage before frost (Levy et al., 2015; VanDyck et al. 2014). Such developmental traps can potentially cause populations to decline, possibly dramatically, as the flight period increases (VanDyck et al. 2014). Knowing how these different responses affect population dynamics is necessary to understand the consequences of phenological shifts, as well as the longer-term effect of increased growing season length on insect populations.

Butterflies are known to be sensitive to changes in temperature and have been widely used as models to study phenological change (Bale et al., 2002). Phenological studies of butterflies have demonstrated advances in adult emergence, which have been attributed to warming climates (Forister \& Shapiro, 2003; Roy \& Sparks, 2000). In contrast to numerous examples of phenological advances in the onset of butterfly flight, few studies have investigated potential changes in the end of flight. In the two studies that have investigated empirical patterns of late-season phenology in butterfly communities, Zipf et al. (2017) and Westwood \& Blair (2010) both observed later end dates of flight activity, correlated with increasing temperatures. These studies are noteworthy in phenological research because much less is known about late-season phenology than early-season phenology (Gallinat et al., 2015; Karlsson, 2014). Nonetheless, in spite of the large body of work on butterfly phenology, we do not know whether phenological changes are beneficial or deleterious responses to changing environments. One recent study has demonstrated that advanced emergence in British Lepidoptera was associated with significantly higher rates of demographic abundance within multivoltine species (MacGregor et al., 2019). Some studies of birds have also generally demonstrated associations between delayed phenology and decreasing abundance trends (Saino et al., 2011; Møller et al., 2008; Both et al., 2006). Understanding the population dynamics associated with phenology is imperative to translating climaterelated phenological changes into their impacts for long-term viability.

One common feature of past research on phenology change is analysis using simple metrics such as first, average, or last observation date. Inferences from such metrics may be limited because first and last observation dates have known biases (Miller-Rushing, 2008) and averages do not capture changes throughout the activity period (Inouye et al., 2019). In this study, we use quantile regression (Cade and Noon, 2003) to evaluate phenological change throughout the activity period. Quantile regression is a statistical modelling technique that enables us to robustly estimate changes in the onset and end of adult flight. Like linear regression, quantile regression generates a slope-intercept line through a specific part of the distribution. Linear regression minimizes squared deviations in the response variable around a trend, whereas quantile regression minimizes the absolute deviations from a trend, subject to the constraint that some proportion of the data be below the line (e.g. the 0.1 quantile, or $10^{\text {th }}$ percentile, fits a line that minimizes absolute deviations with $10 \%$ of observations below the line). Quantile regression uses the complete data set to fit this line, and so it differs from fitting a line to the first or last $\mathrm{x} \%$ of data points, an ad hoc technique that has occasionally been used in ecological studies of phenology (Zipf, et al., 2017; Brooks et al., 2014; Polgar et al., 2013). To date, a handful of studies have used quantile regression to study trends in phenology, mostly in the context of bird migration., These studies have revealed that changes in phenology are not uniform (e.g., Barton and Sandercock, 2018; Gimesi et al., 2012; Gordo et al., 2013). Although under-used, quantile regression represents a formal and robust technique for evaluating changes in phenology throughout the activity period.

Here, we quantify long-term trends in phenology and abundance of butterflies using 27 years of citizen science records from the Massachusetts Butterfly Club (hereafter MBC). Using these observational data for Massachusetts butterflies, we test the relationship between year-to-year changes in flight phenology and abundance. For each species, we estimate abundance trends through time using list length analysis, updating previous analyses of an earlier subset of the same data (Breed et al., 2013), and analyses of counts individuals. 
We test whether changes in the onset of activity, the end of activity, the average date, and the flight period are associated with increases or declines in abundance. We also evaluate relationships between life history traits, trends in phenology, and trends in abundance using structural equation modelling to elucidate the potential mechanistic pathways. We compare our results to a recent study which documented similar associations between phenology and abundance for British (MacGregor et al., 2019). Finally, we discuss the implications of our findings for insect population viability in their phenological response to global change.

\section{Methods}

Study system : The Massachusetts Butterfly Club (MBC) is a group of citizen scientists which documents sightings of butterflies and maintains a database of observation records. The MBC compiles records of butterfly sightings from organized group trips and as reported opportunistically by individuals. The current club database of records from 1992-2018 includes 30,707 species lists from these reports (hereafter referred to as trips) encompassing 162,670 sightings of 99 different butterfly species. We thinned this to 10,884 trips encompassing 126,087 sightings of 89 species suitable for analysis using multiple criteria. First, although the database includes historic records used to build the Atlas of Massachusetts Butterflies, we excluded records prior to 1992, the year in which the club started to record large numbers of lists (i.e., > 1200 sightings/year). Next, following Breed et al. (2013), trips with $<5$ species seen were excluded, to minimize the effect of anecdotal sightings (see Appendix S1 in Supporting Information ). Unlike Breed et al (2013), we combined and retained records for two species groups. Canadian Tiger Swallowtail Paplio canadensis and Eastern Tiger Swallowtail Paplio glaucus records were combined (rather than excluded) because they are known to hybridize and can sometimes be difficult to visually distinguish. Spring AzureCelastrina ladon and Summer Azure Celastrina neglecta were also combined because of a change in species reporting within the MBC during the study period. With these two exceptions, species were excluded if during the study period they underwent a taxonomic shift or realignment, or if there was an outbreak of the population uncharacteristic of conventional population dynamics (following Breed et al. 2013; see Appendix S2 ). Species were also excluded if there were fewer than 15 observations before the year 2000, to prevent outliers or a lack of available data from driving trends (SeeAppendix S4 ). MBC records were processed into a database, generating 89 speciesspecific lists of all trips. Each species file included presence/absence of the species on each trip, the date of each trip, the number of individuals of that species seen on each trip, and the total number of species seen on each trip (see Appendix $S 1$ ).

To interpret patterns of phenology and abundance change we compiled data on two life history traits: voltinism and range type. Following Breed et al. (2013), voltinism was categorized as either obligately univoltine (a single generation per year) or multivoltine (two or more generations per year). Categorization agreed with Breed et al. (2013), with a few exceptions in which scatter plots of observation day of year supported an update (see Appendix S4 ). Following Breed et al. (2013), we categorized species' range type based on the center of their geographic range distribution, relative to Boston, Massachusetts (the approximate mid-latitude for the state of Massachusetts). Species were ordinally identified as having ranges centered north, central, or south of the latitude of Boston (species classified as northern would therefore be closer to the southern limit of their range).

\section{Trends in abundance and phenology}

We estimated relative abundance using 'list length' analysis (Breed et al., 2013; Szabo et al., 2010; Franklin, 1999). List length analysis uses the total number of species observed in an outing, i.e. the list's length, as a proxy for search effort. List length may be more reliable than observer hours, observer miles, or number of observers because the probability of seeing a species does not scale directly with these metrics for observation (Szabo et al., 2010; Franklin, 1991). Relative abundance of each species was estimated using a binomial generalized linear mixed model (GLMM) with fixed effects of year and list length, and a presence/absence response (see Appendix S2 ). We also included year as a random effect to account for interannual variation in relative abundance of species. The yearly slope coefficients of these models represent changes in relative abundance, measured as the change in species presence on lists over time. Analyses were implemented in $\mathrm{R}$ using the lme4 package (R Core Team, 2018; Bates et al., 2014). To supplement inference from list length 
analysis, we analyzed trends in the number of butterflies of each species seen per trip. These counts are a very coarse metric of abundance because they were collected idiosyncratically (not with a uniform survey protocol). However, congruent results from analyzing these counts and list length analysis would suggest that both are reasonable metrics of abundance. Count models used Poisson GLMMs with fixed effects of year and random effects of year. Models were fit using the glmer() function from the package 'lme4' (Bates et al., 2014).

We used quantile regression (Cade and Noon, 2003) to estimate trends in the onset, end, and total length of observations of each species across years. Changes in the onset of flight were estimated as the slope of the 0.1 quantile of observation dates for each species as a function of year. Therefore, negative values indicate advances in phenology and positive values indicate delays in phenology. Changes in the end of flight were estimated as the slope of the 0.9 quantile of observation dates of each species as a function of year. Therefore, negative values indicate advances and positive values indicate delays. The change in the total flight period was estimated as the difference between the 0.9 and 0.1 quantile slopes, where negative values indicate shortening flight periods and positive values indicate lengthening flight periods. Quantile regression was carried out using the $\mathrm{rq}()$ function from the package 'quantreg' (Koenker, 2019). To make an explicit comparison between the changes in phenology of Massachusetts and British butterflies from Macgregor et al. (2019), we also use linear regression to measure the annual change in mean observation date as a function of time with year included as both a fixed and random effect. Negative values again indicate advances in the mean observation date and positive values indicate delays. We used the glmer() function from the package 'Ime4' (Bates et al., 2014).

As a simple metric of the association between changes in phenology and changes in abundance, we correlated metrics of phenological change (slope for each species with respect to time of the 0.1 quantile, 0.9 quantile, flight period, and mean date) with changes in abundance (slope for each species from list length analysis). Because all slopes were measured with error, we verified the relationship with parametric bootstrapping, i.e., resampling estimates for each species from a random normal distribution using the true mean and standard deviation for each species (10,000 bootstrap samples). We evaluated taxonomic effects as predictors of all response variables. Trends in abundance and various phenology metrics were not associated with taxonomic groups (at the family or genus level), and these effects are not discussed further (seeAppendix S3 ).

\section{Structural Equation Models:}

We observed a strong association between changes in flight period and changes in abundance (see Results). This correlation could be the result of various causal factors. We explored two of these factors using structural equation models (SEMs). SEMs can be used to analyze the effect size and directionality of causal pathways among the variables (Grace et al., 2015). Breed et al. (2013) had previously found that species were more likely to be increasing if they were multivoltine or if our study area (Massachusetts) was north of the center of their range. Our a priori model had a direct effect of range type (northern, central, or southern) on voltinism and abundance trends; voltinism had a direct effect on flight period trends; and range type had a direct effect on flight period (See Appendix S5 ). We scaled each variable in the SEM to $\mathrm{x}=0$ and sd $=1$ such that each per unit change in the response is with respect to 1 change standard deviation of the predictor. This scaling facilitates comparisons between variables with different units.

SEM pathways were built and evaluated using the 'lavaan' package in R (Rosseel et al., 2017). After fitting our a priori model, we explored model fit using the modindices() function to look for correlations that were not included in our initial hypothesis (following Grace et al., 2015). We used this exploratory tool to add additional ecologically plausible relationships among voltinism, range type, and trends in flight period and abundance. We also interpreted the original and updated models to understand the causal relationships between trends in flight period and trends in abundance.

\section{Results}

Trends in Abundance and Phenology: 
Because list length analysis is a metric of relative abundance, average trends in abundance are expected to be centered around 0 across species; this expectation held (mean $=0.003, \mathrm{sd}=0.045$, greatest decline $=-0.137$ (Nymphalis vaualbum Compton tortoiseshell; Fig 1a), greatest increase $=0.190$ (Poanes zabulon Zabulon skipper; Fig 1b)). Trends estimated from count models were also broadly centered around 0 (mean $=0.012$, $\mathrm{sd}=0.057$, greatest decline $=-0.159$ (Nymphalis vaualbum Compton tortoiseshell), greatest increase $=0.213$ (Poanes zabulon Zabulon skipper)). Trends estimated from list length were strongly congruent with trends estimated from counts (Pearson's $\mathrm{r}=0.89, \mathrm{P}<0.001$ ). Therefore, we focus the rest of our analyses on trends estimated from list length analyses (seeAppendix S2 ).

Across 26 years of continuous observation, species were, on average, advancing their onset of flight approximately 0.20 days per year $(\mathrm{sd}=0.42$, range $=$ (advancing) -1.75 days per year for Battus philenor (Pipevine swallowtail; Fig 1c), to (delaying) +1.22 days per year for Vanessa cardui (Painted lady; Fig 1d)) with an estimated $75 \%$ of species advancing their 0.1 quantile observations. Species were, on average, delaying their 0.9 quantile day of year observation approximately 0.04 days per year $(\mathrm{sd}=0.50$, range $=-1.76$ days per year (Nymphalis vaualbum Compton Tortoiseshell), +1.29 days per year (Erynnis horatius Horace Duskywing)). Approximately $58 \%$ of species delayed their 0.9 quantile observations. Species were, on average, increasing their flight period (measured as the difference between the 0.9 quantile trend and 0.1 quantile trend) by 0.16 days per year $(\mathrm{sd}=0.55$ days per year, range $=-1.96$ days per year for Nymphalis vaualbum (Compton tortoiseshell), +2.05 days per year Battus philenor (Pipevine swallowtail). Approximately an estimated $63 \%$ of species increasing their observed flight period.

Trends in the onset of flight activity (0.1 quantile) were negatively correlated with changes in relative abundance, i.e., advancing the start of the flight period was associated with increasing abundance $(\mathrm{r}=-0.27$, $\mathrm{t}=-2.7, \mathrm{df}=87, \mathrm{p}=0.009,98.03 \%$ of bootstrapped correlations $<0$; Fig 2a). Trends in the end of flight activity (0.9 quantile) were positively correlated with changes in relative abundance, i.e., species that were extending their activity later into the year also tended to be increasing in abundance $(\mathrm{r}=0.36, \mathrm{t}=3.59$, $\mathrm{df}=87, \mathrm{p}<0.001 ; 99.07 \%$ of bootstrapped correlations $>0$; Fig $2 \mathrm{~b}$ ). The strongest association in our data was a positive correlation between the annual change in the flight period and the annual change in the relative abundance $(\mathrm{r}=0.54, \mathrm{t}=5.9, \mathrm{df}=87, \mathrm{p}<0.001 ; 99.88 \%$ of bootstrapped correlations $>0 ;$ Fig $2 \mathrm{c})$ such that species elongating their total flight time were increasing in relative abundance.

Mean flight dates were significantly changing in univoltine species (slope of mean day of year observation vs time \pm SE: $-0.27 \pm 0.16$ ) but not for multivoltine species (slope of mean day of year observation vs. time $\pm \mathrm{SE}:-0.03 \pm 0.26$. Overall, there was no significant association between trend in mean date and trend in abundance for all species combined $(\mathrm{r}=0.061, \mathrm{t}=0.574, \mathrm{df}=87, \mathrm{p}=0.568 ; 93.5 \%$ of bootstrapped correlations $>0$ ). Grouping by voltinism and using abundance trends estimated using counts for direct comparison with MacGregor et al. (2019), mean day of year trends were not significantly associated with abundance trends for multivoltine species $(\mathrm{r}=-0.06, \mathrm{t}=-0.43, \mathrm{df}=50, \mathrm{p}=0.672 ; 74.18 \%$ of bootstrapped correlations $<0)$, but were marginally significantly associated with abundance trends for univoltine species $(\mathrm{r}=0.32, \mathrm{t}=2.00, \mathrm{df}=35, \mathrm{p}=0.053 ; 88.75 \%$ of bootstrapped correlations $>0)$.

Structural equation models: Our a prioristructural equation model (Fig. 3) showed significant direct effects of flight period trends (scaled regression coefficient $\pm \mathrm{SE}, \beta=0.472 \pm 0.087)$ and species' range type $(\beta=$ $0.308 \pm 0.101)$ on trends in abundance, which presumably reflects other traits associated with northern vs. southern species. The effect of flight period trends on abundance trends was larger than the direct effects of range type. Differences in flight period were significantly associated with differences in voltinism $(\beta=$ $0.430 \pm 096)$. Compared to univoltine species, multivoltine species more often increased their flight period (days/year $\pm \mathrm{SE}:-0.13 \pm 0.09$ and $0.35 \pm 0.0$ for univoltine and multivoltine, respectively) and increased in relative abundance (trend $\pm \mathrm{SE}$ : $-0.01 \pm 0.01$ and $0.02 \pm 0.01$ for univoltine and multivoltine, respectively). Differences in voltinism were weaker but significantly associated with range type (proportion multivoltine \pm SE: $0.69 \pm 0.06$ and $0.32 \pm .10$ for southern and northern species, respectively). This a priori model demonstrated adequate, but not exceptional fit $\left(\chi^{2}=3.076, \mathrm{df}=2, \mathrm{p}=0.215\right.$; recalling that, in SEMs $\mathrm{p}<$ 0.05 represents significant inconsistency with data). 
Post hoc inspection of modification indices revealed one additional factor that was not present in our $a$ priori model. This missing factor was a relationship between range type and flight period trends; species with southerly ranges were increasing flight periods more than species with northerly ranges (days/year \pm SE: $0.35 \pm 0.07$ and $-0.13 \pm 0.09$, for southern and northern species, respectively), regardless of voltinism. Including this relationship improved model fit $\left(\chi^{2}=0.614\right.$, $\left.\mathrm{df}=1, \mathrm{p}=0.433\right)$, and slightly decreased the strength of the association between voltinism and flight period (updated $\beta=0.381 \pm 0.099$ ).

\section{Discussion}

For butterflies in Massachusetts, changes in abundance were most strongly associated with changes in flight period. Species that have extended their flight period have increased in abundance relative to those that have not. Past studies that have evaluated the effect of warming temperatures have generally demonstrated that species advancing phenological events under warming environmental conditions are generally increasing in abundance or have positive demographic growth (Cleland et al., 2014; Hulme, 2011; Ozgul et al. 2010; Willis et al., 2008; Møller et al., 2008). Species which fail to change their phenology, however, appear to be declining (MacGregor et al. 2019; Cleland et al., 2014; Willis et al., 2008; Møller et al., 2008). In many ways, our results parallel a recent study of Lepidoptera in the Britain (MacGregor et al., 2019). In both studies, changes in some phenological metric were associated with increases in abundance, especially in multivoltine species. However, in contrast to Britain, trends in the mean timing of activity of Massachusetts butterflies were not strongly associated with trends in abundance. Instead, changes in the flight period were the best predictor of trends in abundance. In Massachusetts, changes in flight period were driven more by extended late-season activity than advanced onset of activity, which also contrasts with past work in Britain (Roy and Sparks, 2000). Our results highlight the importance of evaluating the entire temporal distribution of a phenological phenomenon, as opposed to simply using trends in mean observation dates.

One possible mechanistic explanation for the association between extended flight period and increased abundance is an increase in the number of generations per year. In other insect species, climate warming may allow for faster larval development and the production of additional direct-developing generations before adverse winter conditions (MacGregor et al., 2019; Miton and Ferrenberg, 2012; Altermatt, 2009; Tobin et al., 2008). Visual inspection of representative species in our data suggest that at least some populations are adding, at least, a partial generation (Fig. 1b, c \& e). For example, Satyrdotes appalachia (Appalachian Brown, Fig. 1b) may be transitioning from univoltine to bivoltine in our region (Stichter, 2015). If additional generations are the causal mechanism between changes in flight period and increased abundance in multivoltine species, it would suggest that beneficial effects of higher population growth rates (Kerr et al., 2020) and/or more rapid evolution (Chevin et al., 2010) outweigh the potential costs of developmental traps (Van Dyck et al., 2015; Levy et al., 2015). In general, multivoltine butterfly species seem to have higher population growth rates than univoltine species in north-temperate climates (MacGregor et al., 2019; Wepprich et al., 2019; Breed et al., 2013). In one study from a Mediterranean climate, however, multivoltine species showed significantly steeper declines than obligate uni- or bivoltine species. In this ecosystem, seasonal adversity in summer months via drought may have led to a developmental trap (Melero et al., 2016).

Past studies of butterflies in Massachusetts (Breed et al., 2013) and of other Lepidoptera (Pöyry, 2009; Parmesan et al., 1999) have revealed strong patterns of poleward range shifting in response to climate change. In Massachusetts, southern species are increasing in relative abundance, and northern species tend to be declining (Breed et al. 2013). Our structural equation model suggests one causal pathway by which southern species are increasing in relative abundance to some extent because of their capacity to extend their overall flight period. Although the SEM supports variability in voltinism as the strongest driver of trends in abundance, there were also direct effects of species' range type on trends in abundance. These effects presumably reflect other limiting factors such as physiological tolerance or trends in interacting species. For example, Nymphalis vaualbum (Compton Tortoiseshell, Fig. 1a) is a northern species that has recently declined rapidly in the state of Massachusetts. The abrupt shift in abundance suggests a physiological threshold could have been crossed in the past decade.

For at least two species in our data, changes in flight period appeared to be due in part to changes in the 
ability to overwinter in Massachusetts, as opposed to voltinism per se. Poanes zabulon Zabulon skipper (Fig. 1b) and Battus philenor Pipevine swallowtail (Fig. 1c) were formerly considered vagrants. In other words, in the past, individuals of these species moved annually to Massachusetts from populations further south during the summer, but never established resident populations (Stichter, 2015). It seems likely that these species can now successfully overwinter in Massachusetts, as shown by an apparent early season generation (see Fig. $1 \mathrm{~b} \& \mathrm{c}$ ). These trends contrast with two other migratory species, Vanessa cardui (Painted Lady, Fig. 1d) and Danaus plexippus (Monarch, Fig. 1f), both which are non-resident, multi-generational, obligatory migrants, far north of overwintering sites. Both species have delays (not advances) in the onset of spring activity in Massachusetts, and only $V$. cardui showed delayed end of flight activity, while there was no substantial trend in the end of D. plexippus flight in Massachusetts. Both species showed negligible changes in relative abundance in Massachusetts.

Across the community of butterflies in Massachusetts, trends in abundance estimated from counts, as well as trends from the list length analysis, were centered on zero. In other words, approximately equal numbers of Massachusetts species are increasing in abundance as are declining in abundance. Our results contrast with negative average trends reported across butterfly communities in four other regions: Ohio, USA (Wepprich et al. 2019), California, USA (Forister et al. 2011), the UK (Brereton et al. 2018), and Spain (Melero et al. 2016). Unlike Ohio and California, both of which have agricultural development at industrial scales, Massachusetts may be subject to lower levels of agricultural land use intensification. Systematic monitoring rather than ad hoc citizen science observations would be needed to rigorously test whether butterfly communities in Massachusetts are truly more stable in abundance when compared to other regions. Nonetheless, our data suggest a hopeful hypothesis that butterflies may be able to adjust to climate change, if freed from the additional pressure of anthropogenic changes in land use.

Our results highlight the potential for phenological changes to affect population dynamics, and the general importance of phenological flexibility for insect population dynamics in changing environments. Past studies of phenology have rarely evaluated shifts in the end of activity (Zipf al., 2017; Gallinat et al., 2015), despite the demographic importance of late-season events such as entry into diapause (Kerr et al. 2020). Unlike traditional metrics of phenological change, quantile regression (Cade and Noon, 2003) enabled us to estimate trends in both the onset and end of flight across Massachusetts butterflies. In Massachusetts, changes in the total flight period and end of activity were associated more strongly with trends in abundance than onset or mean trends. In Lepidoptera, a diversity of cues and mechanisms, both genetic and plastic (Lindestad et al., 2019; Kozak et al., 2019), shape patterns of phenology and voltinism. Understanding these mechanisms would be a valuable direction for future research if our goal is to predict changes in phenology and abundance in new systems. This case study highlights how phenological changes relate to population dynamics, and the importance of phenological changes for population viability in changing environments.

\section{Acknowledgements}

The authors thank the Massachusetts Butterfly Club (especially Mark Fairbrother, Sharon Stichter \& Steve Moore) for graciously providing us with their extensive database records. This work was funded by a DOD SERDP award (RC-2700) to E. Crone and NSF DEB award (1257251) to E.B.D.

\section{References}

Altermatt, F. (2010). Climatic warming increases voltinism in European butterflies and moths.Proc. R Soc. Lond. [Biol], 277, 1281-1287.

Bale, J. S. (2002). Insects and low temperatures: from molecular biology to distributions and abundance. Philos. Trans. R. Soc. B. , 357, 849-862

Bale, J. S., \& Hayward, S. A. L. (2010). Insect overwintering in a changing climate. J. Exp. Biol. , 213, 980-994.

Barton, G. G., \& Sandercock, B. K. (2018). Long-term changes in the seasonal timing of landbird migration on the Pacific Flyway. Condor, 120, 30-46. 
Bates, D., Maechler, M., Bolker, B., \& Walker, S. (2014). lme4: Linear mixed-effects models using Eigen and S4. $R$ package version, 1, 1-23.

Both, C., Bouwhuis, S., Lessells, C. M., \& Visser, M. E. (2006). Climate change and population declines in a long-distance migratory bird. Nature , 441, 81 .

Breed, G. A., Stichter, S. \& Crone, E. E. (2013). Climate-driven changes in northeastern US butterfly communities. Nat Clim Change, 3, 142-145.

Brereton, T. M., Botham, M. S., Middlebrook, I., Randle, Z., Noble, D., \& Roy, D. B. (2014). United Kingdom butterfly monitoring scheme report for 2014. Centre for Ecology and Hydrology and Butterfly Conservation

Brooks, S. J., Self, A., Toloni, F., \& Sparks, T. (2014). Natural history museum collections provide information on phenological change in British butterflies since the late-nineteenth century. Int. J. Biometeorol. , 58, $1749-1758$.

Cade, B. S. \& Noon, B. R. (2003). A gentle introduction to quantile regression for ecologists.Front. Ecol. Envrion., 1, 412-420.

Chevin, L. M., \& Lande, R. (2010). When do adaptive plasticity and genetic evolution prevent extinction of a density-regulated population? Evolution, 64, 1143-1150.

Cleland, E.E., Allen J. M., Crimmins, T.M., Dunne, J.A., Pau, S., Traver, S.E., Zavaleta, E.S., Wolkovich, E.M. (2012). Phenological tracking enables positive species responses to climate change.Ecology, 93, 17651771.

Fric, Z. F., Rindoš, M., \& Konvička, M. (2020). Phenology responses of temperate butterflies to latitude depend on ecological traits. Ecol. Lett. , 23, 172-180.

Forister, M. L., Shapiro, A. M. (2003). Climatic trends and advancing spring flight of butterflies in lowland California. Glob. Change Biol., 9, 1130-1135.

Forister M. L., Jahner J. P., Casner K. L., Wilson J. S., Shapiro A. M. (2011). The race is not to the swift: long-term data reveal pervasive declines in California's low-elevation butterfly fauna. Ecology , 92, $2222-2235$

Franklin, D. C. (1999). Evidence of disarray amongst granivorous bird assemblages in the savannas of northern Australia, a region of sparse human settlement. Biol. Cons., 90, 53-68.

Forrest, J., \& Miller-Rushing, A. J. (2010). Introduction: Toward a synthetic understanding of the role of phenology in ecology and evolution. Philos. Trans. R. Soc. B., 3101-3112.

Gallinat, A. S., Primack, R. B., \& Wagner, D. L. (2015). Autumn, the neglected season in climate change research. Trends Ecol. Evolut., 30, 169-176.

Gimesi, L., Homoródi, R., Hirka, A., Szaboki, C., \& Hufnagel, L. (2012). The effect of climate change on the phenology of moth abundance and diversity. Appl. Ecol. Environ. Res., 10, 349-363.

Gordo, O., Tryjanowski, P., Kosicki, J. Z., \& Fulín, M. (2013). Complex phenological changes and their consequences in the breeding success of a migratory bird, the white stork Ciconia ciconia. J. Anim. Ecol., $82,1072-1086$.

Grace, J. B., Scheiner, S. M., \& Schoolmaster Jr, D. R. (2015). Structural equation modeling: building and evaluating causal models: Chapter 8. (Ecological Statistics: Contemporary theory and application) Oxford Scholarship Online, pp. 168-199.

Grevstad, F. S., \& Coop, L. B. (2015). The consequences of photoperiodism for organisms in new climates. Ecol. Appl. , 25, 1506-1517. 
Hulme, P. E. (2011). Contrasting impacts of climate-driven flowering phenology on changes in alien and native plant species distributions. New Phytol. , 189, 272-281.

Inouye, D. W., Barr, B., Armitage, K. B., \& Inouye, B. D. (2000). Climate change is affecting altitudinal migrants and hibernating species. PNAS , 97, 1630-1633.

Inouye, B. D., Ehrlen, J., \& Underwood, N. (2019). Phenology as a process rather than an event: from individual reaction norms to community metrics. Ecol. Monograph, 89, e01352.

Karlsson, B. (2014). Extended season for northern butterflies. Int. J. Biometeorol. , 58, 691-701.

Kerr, N. Z., Wepprich, T., Grevstad, F., Dopman, E. B., Chew, F. S., Crone, E. E. (2020). Developmental trap or demographic bonanza? Opposing consequences of earlier phenology in a changing climate for a multivoltine butterfly. Glob. Change Biol., 26, 2014-2027.

Kerr, N. Z., Crone, E. E., Chew, F. S. (2019). Life history trade-offs are more pronounced for a noninvasive, native butterfly compared to its invasive, exotic congener. Pop. Ecol ., 62: 119-133.

Koenker, R., Portnoy, S., Ng, P. T., Zeileis, A., Grosjean, P., \& Ripley, B. D. (2019). Package 'quantreg'.

Levy, R. C., Kozak, G. M., Wadsworth, C. B., Coates, B. S. \& Dopman, E. B. (2015). Explaining the sawtooth: Latitudinal periodicity in a circadian gene correlates with shifts in generation number. $J$ Evol. Biol., 28, 40-53.

Lindestad, O., Wheat, C.W., Nylin, S. and Gotthard, K., (2019). Local adaptation of photoperiodic plasticity maintains life cycle variation within latitudes in a butterfly. Ecology, 100, p.e02550.

Macgregor, C. J., Thomas, C. D., Roy, D. B., Beaumont, M. A., Bell, J. R., Brereton, et al. (2019). Climate-induced phenology shifts linked to range expansions in species with multiple reproductive cycles per year. Nature, 10, 1-10.

Melero, Y., Stefanescu, C., \& Pino, J. (2016). General declines in Mediterranean butterflies over the last two decades are modulated by species traits. Biol. Cons., 201, 336-342.

Mitton, J. B., \& Ferrenberg, S. M. (2012). Mountain pine beetle develops an unprecedented summer generation in response to climate warming. Amer. Nat., 179, 163-171.

Moller, A. P., Rubolini, D. \& Lehikoinen, E. (2008). Populations of migratory bird species that did not show a phenological response to climate change are declining. PNAS, 105, 16195-16200.

Ozgul, A., Childs, D. Z., Oli, M. K., Armitage, K. B., Blumstein, D. T., Olson, L., et al. (2010). Coupled dynamics of body mass and population growth in response to environmental change. Nature, 466, 482-485.

Parmesan, C., Ryrholm, N., Stefanescu, C., Hill, J. K., Thomas, C. D., Descimon, H., et al. (1999). Poleward shifts in geographical ranges of butterfly species associated with regional warming. Nature, 399, 579-583.

Parmesan, C., \& Yohe, G. (2003). A globally coherent fingerprint of climate change impacts across natural systems. Nature , 421, 37-42

Polgar, C. A., \& Primack, R. B. (2011). Leaf-out phenology of temperate woody plants: from trees to ecosystems. New phytol. , 191, 926-941.

Polgar, C. A., Primack, R. B., Williams, E. H., Stichter, S., \& Hitchcock, C. (2013). Climate effects on the flight period of Lycaenid butterflies in Massachusetts. Biol. Cons., 160, 25-31.

Poyry, J., Luoto, M., Heikkinen, R. K., Kuussaari, M., \& Saarinen, K. (2009). Species traits explain recent range shifts of Finnish butterflies. Glob. Change Biol., 15, 732-743.

R Core Team (2019). R: A language and environment for statistical computing . R Foundation for Statistical Computing, Vienna, Austria. URL https://www.R-project.org/ 
Ramula, S. Johansson, J., Linden, A. \& Jonzen, N. (2015). Linking phenological shifts to demographic change. Clim. Res., 63, 135-144.

Rathcke, B., \& Lacey, E. P. (1985). Phenological patterns of terrestrial plants. Annu. Rev. Ecol. Evol. Syst. , 16, 179-214.

Roy D. B. \& Sparks, T. H. (2000). Phenology of British Butterflies and climate change. Glob. Change Biol., $6,76-81$.

Saino, N., Ambrosini, R., Rubolini, D., von Hardenberg, J., Provenzale, A., Huppop, K., et al. (2011). Climate warming, ecological mismatch at arrival and population decline in migratory birds. Proc R Soc Lond [Biol], 278, 835-842.

Stichter, S. (2015).Butterflies of Massachusetts . Available at: https://www.butterfliesofmassachusetts.net/index.htm. Last accessed 28 January 2020.

Szabo, J. K., Vesk, P. A., Baxter, P. W. J. \& Possingham, H. P. (2010). Regional avian species declines estimated from volunteer-collected long-term data using List Length Analysis. Ecol. Appl., 20, 2157-2169.

Tobin, P. C., Nagarkatti, S., Loeb, G., \& Saunders, M. C. (2008). Historical and projected interactions between climate change and insect voltinism in a multivoltine species. Glob. Change Biol. , 14, 951-95.

Van Dyck, H., Bonte, D., Puls, R., Gotthard, K., \& Maes, D. (2015). The lost generation hypothesis: could climate change drive ectotherms into a developmental trap? Oikos , 124, 54-61.

Wepprich, T., Adrion, J. R., Ries, L., Wiedmann, J., \& Haddad, N. M. (2019). Butterfly abundance declines over 20 years of systematic monitoring in Ohio, USA. PloS ONE , 14 e0216270.

Westwood, A. R., \& Blair, D. (2010). Effect of regional climate warming on the phenology of butterflies in boreal forests in Manitoba, Canada. Environ. Entomol. , 39, 1122-1133.

Willis, C. G., Ruhfel, B., Primack, R. B., Miller-Rushing, A. J. \& Davis, C. C. (2008). Phylogenetic patterns of species loss in Thoreau's woods are driven by climate change. PNAS, 105, 17029-17033.

Zipf, L., Williams, E. H., Primack, R. B. \& Stichter, S. (2017). Climate effects on late-season flight times of Massachusetts butterflies. Int. J. Biometeorol., 61, 1667-1673.

\section{Figure legends}

Figure 1 Paired day of year observations and change in presence for select species over the study period (1992-2018). For each species, the top plot graphs observations by the year and numeric day of year of every sighting throughout the study period, slightly jittered for visibility; The upper line represents the end of flight (estimated as the 0.9 quantile day of year observation) and the bottom line represents the onset of flight (estimated as the 0.1 quantile day of year observation). For each species, the bottom plot describes the change in abundance over the study period; each point represents the total proportion of trips on which the species was present for each year, the slopes of these plots reflect trends in relative abundance incorporated into the list length model. Axis ticks for all plots represent the years 2000 and 2010.

Figure 2. Correlations between annual changes in relative abundance and 0.1 quantile (a), 0.9 quantile (b), flight period (c). Each point (a, b \& c) represents a single species, shaped by voltinism and colored by range type. $\mathrm{Y}$ axis values represent the annual change in relative abundance estimated from list length analysis. (a) change in start of flight is measured as the slope of the 0.1 quantile (advances or delays); (b) change in the end of flight is measured as the slope of the 0.9 quantile (advances or delays); (c) change in total flight period is measured as the difference between the 0.9 and 0.1 quantiles (elongations or contractions).

Figure 3. Structural equations models. Lines indicate the direction of causality. Listed adjacent to lines are the scaled regression coefficients, the relative magnitude of the effects with respect to one changing standard deviation of the predictor. The a priori model is represented by solid lines, and post hocmodifications are represented by dashed lines. 
Figure 1.
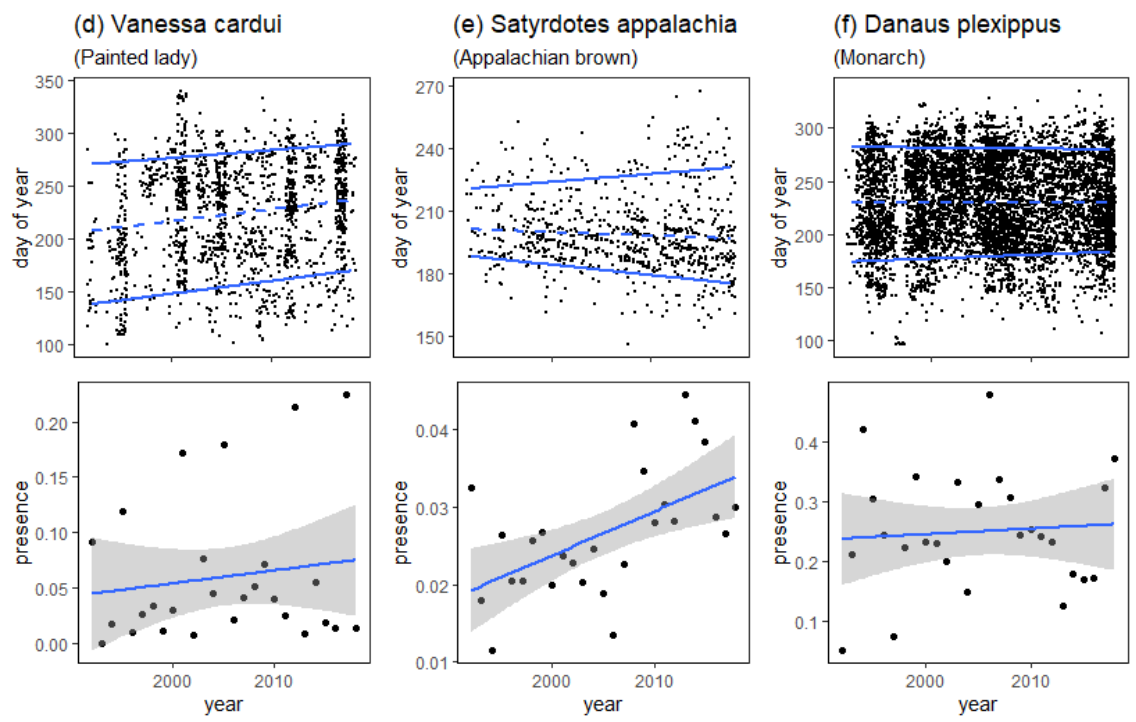

Figure 2. 

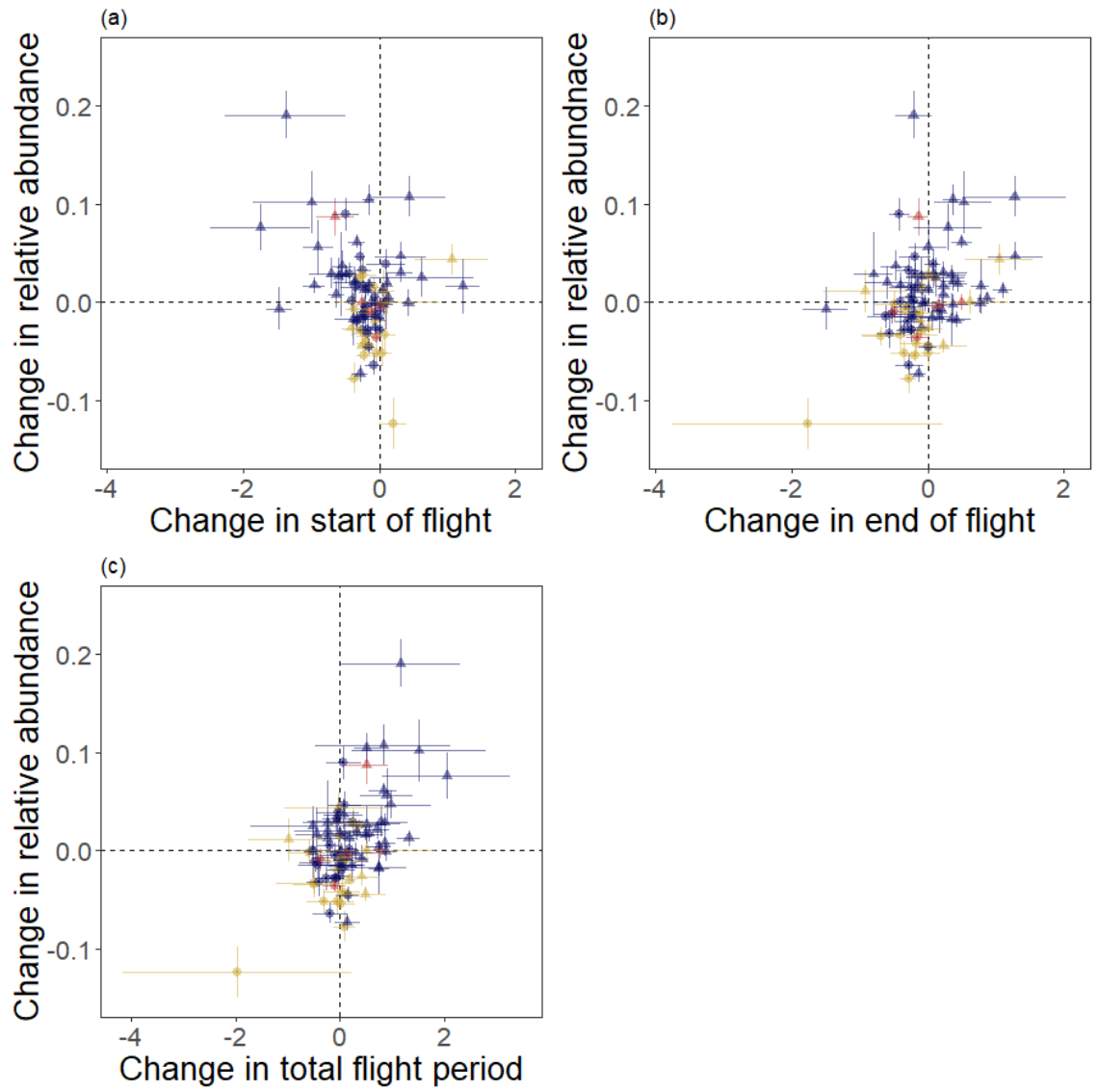

Figure 3. 